\title{
Adaptive Hybrid Control of Vehicle Semiactive Suspension Based on Road Profile Estimation
}

\author{
Yechen Qin, ${ }^{1}$ Mingming Dong, ${ }^{1}$ Reza Langari, ${ }^{2}$ Liang Gu, ${ }^{1}$ and Jifu Guan ${ }^{1}$ \\ ${ }^{1}$ School of Mechanical Engineering, Beijing Institute of Technology, Beijing 100081, China \\ ${ }^{2}$ Department of Mechanical Engineering, Texas A\&M University, College Station, TX 77840, USA
}

Correspondence should be addressed to Liang Gu; guliang@bit.edu.cn

Received 24 January 2015; Accepted 30 April 2015

Academic Editor: Mickaël Lallart

Copyright (c) 2015 Yechen Qin et al. This is an open access article distributed under the Creative Commons Attribution License, which permits unrestricted use, distribution, and reproduction in any medium, provided the original work is properly cited.

\begin{abstract}
A new road estimation based suspension hybrid control strategy is proposed. Its aim is to adaptively change control gains to improve both ride comfort and road handling with the constraint of rattle space. To achieve this, analytical expressions for ride comfort, road handling, and rattle space with respect to road input are derived based on the hybrid control, and the problem is transformed into a MOOP (Multiobjective Optimization Problem) and has been solved by NSGA-II (Nondominated Sorting Genetic Algorithm-II). A new road estimation and classification method, which is based on ANFIS (Adaptive Neurofuzzy Inference System) and wavelet transforms, is then presented as a means of detecting the road profile level, and a Kalman filter is designed for observing unknown states. The results of simulations conducted with random road excitation show that the efficiency of the proposed control strategy compares favourably to that of a passive system.
\end{abstract}

\section{Introduction}

The increasing demands of the market have led to the emergence of different types of vehicle suspension systems. In terms of energy consumption, vehicle suspension can be divided into three types: passive suspension, semiactive suspension, and active suspension. Passive suspension is the most popular form, and through careful selection of spring and damper coefficients, a compromise solution is derived for ride comfort and road handling. Due to the conflicting of these two criterions, the optimal performance of a passive suspension system can only be achieved in a certain frequency range $[1,2]$. Active suspension system has thus emerged to overcome this disadvantage, showing improved performance across a wider frequency range [35]. The defects of active suspension system, however, such as inherent stability problems, high energy costs, and extra power source requirements, restrict its application in commercial vehicles [6]. Semiactive suspension system has hence been created to address this, offering a compromise between performance and cost $[7,8]$. Semiactive suspension system typically equips a controllable damper with an extra energy input of only few Watts, and their control bandwidth is even higher than that of active suspension systems [6]. Semiactive suspension system can be further divided into two parts; the first is adaptive semiactive suspension system, which can slowly change damping coefficient according to road conditions, and has been applied in new Audi A6 Allroad Quattro. As for the second one, the semiactive suspension system, it can rapidly change damping coefficient according to states feedback. Since the first semiactive suspension control strategy, skyhook control, which was proposed in the 1970s, a large number of innovative control strategies have been proposed to improve the criterions mentioned above. Prominent examples of such strategies include the groundhook [9, 10], robust control [11], and MPC (Model Predictive Control) $[12,13]$. To evaluate the performance of a vehicle suspension system, three criterions are widely used $[6,14-17]$.

(1) Ride comfort. To isolate the vehicle body and passengers from road disturbances, the performance in terms of two frequency ranges needs to be improved: the natural frequency for the vehicle body $(1-1.5 \mathrm{~Hz})$, and the frequency range to which humans are sensitive $(4-8 \mathrm{~Hz})[18]$. To simplify the calculation process, 
the acceleration of the sprung mass is typically used as the metric upon which comparison is based $[1,4$, 7, 15-17, 19].

(2) Road handling. This criterion measures the ability of a suspension system to maintain contact with the road surface [6]. Generally speaking, tyre force or tyre deflection is normally chosen for use as a comparison metric $[1,15]$. In order to obtain better acceleration, braking and steering ability when driving in worse road conditions, the tyre force, or deflection should be small.

(3) Rattle space (working space). The rattle space represents the distance between the sprung and unsprung mass. This is a constraint for the suspension system, and under the assumption that the road input is a Gaussian distribution process [20] and the whole system is linear, the variance of rattle space should be designed not to exceed $\pm 1 / 3$ of the constraint value. This will ensure that the rattle space remains within the constraint range $99.7 \%$ of the time $[3,4]$.

To combine the merits of both skyhook and groundhook suspension systems for ride comfort and road handling, respectively, the hybrid control is proposed $[19,21,22]$. The hybrid control is a typical semiactive suspension control strategy since it can rapidly adjust damping coefficient according to system states feedback. By adjusting the weighting of hybrid control rule, operators can change the suspension's operating characteristics from being ride comfort oriented to being road handling oriented, to suit whatever suspension performance they most desire at that time.

For the suspension hybrid control that have been explored in the literatures, little focus has been given to the choice of damping coefficients for hybrid control systems and how to cooperate this strategy with varying road condition. To address this, a road estimation based semiactive suspension hybrid control strategy is proposed in this paper. The main contributions and innovations of this paper are as follows. Firstly, the analytical expressions for three performance criterions with respect to road excitation are derived, and the choice of damping coefficients is transformed into a MOOP (Multiobjective Optimization Problem), which is solved by NSGA-II (Nondominated Sorting Genetic Algorithm-II) [23, 24]. Secondly, the cooperation between hybrid control and road estimation is built. A new road classification method based on ANFIS (Adaptive Neurofuzzy Inference System) and wavelet transform is presented for estimating the road profile level [25], so that the damping coefficients can adaptively vary according to road condition and the according solution of MOOP.

This paper proceeds as follows. Section 2 briefly introduces the road model and its generation in the time domain; Section 3 presents the quarter vehicle model and the control strategy; Section 4 illustrates the calculation of damping coefficients with NSGA-II; Section 5 discusses road profile estimation and classification; Section 6 describes the design of observer; Section 7 contains numerical simulations for different road levels; and a conclusion is drawn at last.

\section{Road Model}

The distance between the road surface and the base plate is typically defined as a function of road irregularities. Often, the road profile is assumed to be a homogeneous and isotropic Gaussian random process, and its statistical characteristics can be described by Power Spectral Density (PSD) [20]. According to ISO 8601 [26], the PSD of road roughness can be defined as

$$
G_{q}(n)=G_{q}\left(n_{0}\right)\left(\frac{n}{n_{0}}\right)^{-W},
$$

where $n$ is spatial frequency in $\mathrm{m}^{-1}$ and $n_{0}$ is reference spatial frequency with value of $0.1 \mathrm{~m}^{-1} . G_{q}\left(n_{0}\right)$ is the PSD value in the reference spatial frequency in $\mathrm{m}^{3}$, and increasing values of $G_{q}\left(n_{0}\right)$ are assigned for different road levels ranging from A (very good) to $\mathrm{H}$ (very poor). $W$ is termed waviness and reflects the approximate frequency structure of the road profile, commonly taken as $W=2$. During the application process, some researchers have however noted two problems with (1):

(1) When the spatial frequency approximates zero, the PSD of the road profile will approach infinity [20,27].

(2) According to actual road measurements, the PSD calculated by (1) will always overestimate the amplitude of the road in the low frequency sections $[4,20]$.

Because of this, another formulation for calculating road profile PSD has been suggested by $[17,28]$ and is used here, as shown in the following:

$$
G_{q}(n)=\frac{\alpha \rho^{2}}{\pi\left(\alpha^{2}+n^{2}\right)},
$$

where $\alpha$ is the road characteristic parameter in $\mathrm{m}^{-1}$ and $\rho$ is the road variance in $\mathrm{m}$. The values of both $\alpha$ and $\rho$ are presented in Table 1 [29]. It should be noted that the values in Table 1 have been carefully validated according to the standard road level defined by the ISO. The road profile in the time domain can be modelled as a first order linear process by $[2,16,28]$

$$
\dot{q}(t)=-\alpha v q(t)+w(t),
$$

where $q(t)$ is road unevenness in $\mathrm{m}, v$ is the vehicle velocity in $\mathrm{km} / \mathrm{h}$, and $w(t)$ is a white noise series with covariance shown as follows:

$$
\operatorname{cov}[w(t)]=E[w(t) w(t+\tau)]=2 \rho^{2} a v \delta(\tau),
$$

where $\delta(\cdot)$ is the Dirac delta function.

\section{Quarter Vehicle Model}

In this section, the hybrid control strategy and corresponding quarter vehicle model are created, and analytical expressions for sprung mass acceleration, tyre force, and rattle space with respect to road excitation are derived. 
TABLE 1: Values of road model parameters.

\begin{tabular}{lcc}
\hline Road level & $\alpha / \mathrm{m}^{-1}$ & $\rho / \mathrm{m}$ \\
\hline A & 0.111 & 0.0377 \\
B & 0.111 & 0.0754 \\
C & 0.111 & 0.151 \\
D & 0.111 & 0.302 \\
E & 0.111 & 0.603 \\
F & 0.111 & 1.206 \\
G & 0.111 & 2.413 \\
H & 0.111 & 4.825 \\
\hline
\end{tabular}

\subsection{Hybrid Control}

3.1.1. Skyhook Control. The purpose of skyhook control is to isolate the sprung mass from external vibration. In this case, a virtual damper is installed between the sprung mass and inertial inference. For practical implementation, however, an equivalent damper is designed between the sprung and unsprung mass. In order to mimic the behaviour of ideal skyhook damping, the following control rules are needed to be satisfied [7]:

$$
F_{\text {sky }}= \begin{cases}c_{\text {sky }}\left(\dot{x}_{b}\right), & \text { if }\left(\dot{x}_{b}-\dot{x}_{w}\right) \cdot \dot{x}_{b} \geq 0 \\ c_{\min }\left(\dot{x}_{b}-\dot{x}_{w}\right), & \text { if }\left(\dot{x}_{b}-\dot{x}_{w}\right) \cdot \dot{x}_{b}<0 .\end{cases}
$$

3.1.2. Groundhook Control. To improve road handling, a groundhook control may be utilised [9]. Similar to the skyhook control, a virtual damper is placed between the unsprung mass and inertial interference. The control algorithm can be expressed as $[30,31]$

$$
F_{\text {grd }}= \begin{cases}c_{\text {grd }}\left(\dot{x}_{w}\right), & \text { if }-\left(\dot{x}_{b}-\dot{x}_{w}\right) \cdot \dot{x}_{w} \geq 0 \\ c_{\min }\left(\dot{x}_{b}-\dot{x}_{w}\right), & \text { if }-\left(\dot{x}_{b}-\dot{x}_{w}\right) \cdot \dot{x}_{w}<0 .\end{cases}
$$

3.1.3. Hybrid Control. In order to combine the advantages of the above two strategies, the concept of hybrid control is proposed. Hybrid control can be described as a linear combination of both skyhook and groundhook control strategies. A typical expression of hybrid control is $[19,21,22]$

$$
F_{d}=\eta F_{\text {sky }}-(1-\eta) F_{\text {grd }},
$$

where $\eta \in[0,1]$ is the weight factor for the hybrid control. The value of $\eta$ can be adjusted subjectively by operator to decide which part is more important during driving process. A value of $\eta=0.2$, for example, can be used if the operator desires to achieve better road handling performance at the expense of ride comfort.

For individual skyhook and groundhook control, the problem of how to choose the damping coefficients is wellstudied in previous research $[1,32,33]$. For hybrid control, however, the matter becomes more complicated since the choice of damping coefficients for each individual control strategy will affect the other, and to the authors' best knowledge, little research has been done to the choice of damping coefficients for hybrid control. This paper hence proposes a new method for solving the problem: deriving the analytical expressions for different criterions and calculating the damping coefficients for both the skyhook and the groundhook control with MOOP.

3.2. System Model and Response to Road Excitation. The structure of an ideal hybrid control model is shown in Figure 1(a).

Since the structure in Figure 1(a) cannot be realised from a practical viewpoint, an equivalent alternative model is shown in Figure 1(b), where $F_{d}$ represents the controllable damping force. As the purpose of this paper is to calculate the damping coefficients for different road levels, $F_{d}$ is expressed as:

$$
F_{d}=c_{\mathrm{sky}} \cdot \dot{x}_{b}-c_{\mathrm{grd}} \cdot \dot{x}_{w} .
$$

Due to the limitations of actual dampers, that is, the limited output force, a constraint rule is applied here:

$$
F_{d}^{\text {output }}= \begin{cases}F_{d}^{\max }, & \text { if } F_{d}>F_{d}^{\max } \\ F_{d}, & \text { if } F_{d}^{\max }>F_{d}>F_{d}^{\min } \\ F_{d}^{\min }, & \text { if } F_{d}^{\min }>F_{d} .\end{cases}
$$

The dynamic equations of the model shown in Figure 1(b) are hence given by:

$$
\begin{aligned}
& m_{b} \ddot{x}_{b}+k_{s}\left(x_{b}-x_{w}\right)+F_{d}=0, \\
& m_{w} \ddot{x}_{w}+k_{s}\left(x_{w}-x_{b}\right)+k_{t}\left(x_{w}-x_{r}\right)+c_{t}\left(\dot{x}_{w}-\dot{x}_{r}\right) \\
& \quad-F_{d}=0 .
\end{aligned}
$$

Taking Laplace transforms for (10), transfer functions for the acceleration of sprung mass, displacement of unsprung mass, tyre force, and rattle space with respect to road input can be expressed as follows:

$$
\begin{aligned}
& H(s)_{\ddot{x}_{b} \sim x_{r}}=\frac{X_{b}(s)}{X_{r}(s)}=\frac{c_{\mathrm{grd}} c_{t} s^{4}+\left(c_{\mathrm{grd}} k_{t}+c_{t} k_{s}\right) s^{3}+k_{s} k_{t} s^{2}}{A}, \\
& H(s)_{x_{w} \sim x_{r}} \\
& =\frac{X_{w}(s)}{X_{r}(s)} \\
& =\frac{c_{t} m_{b} s^{3}+\left(m_{b} k_{t}+c_{\mathrm{sky}} c_{t}\right) s^{2}+\left(c_{\mathrm{sky}} k_{t}+c_{t} k_{s}\right) s+k_{s} k_{t}}{A}, \\
& H(s)_{f_{D} \sim x_{r}}=k_{t}\left(\frac{X_{w}(s)}{X_{r}(s)}-1\right)=k_{t} \frac{D}{A}, \\
& H(s)_{\left(x_{b}-x_{w}\right) \sim x_{r}} \\
& =\frac{X_{w}(s)}{X_{r}(s)} \\
& =\frac{-c_{t} m_{b} s^{3}+\left(c_{\mathrm{grd}} c_{t}-m_{b} k_{t}-c_{\mathrm{sky}} c_{t}\right) s^{2}+\left(c_{\mathrm{grd}} k_{t}-c_{\mathrm{sky}} k_{t}\right) s}{A},
\end{aligned}
$$




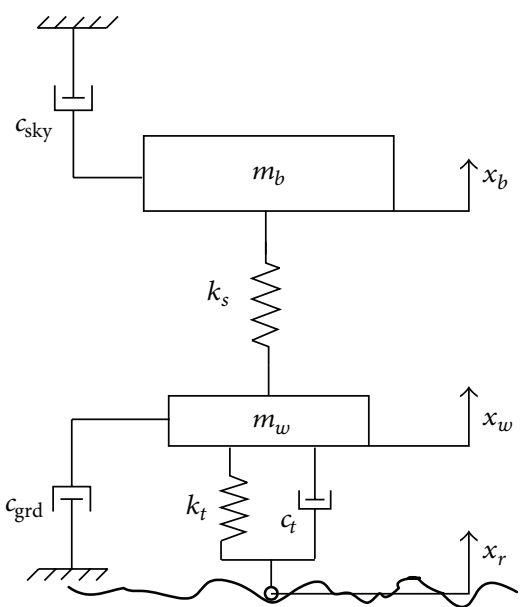

(a)

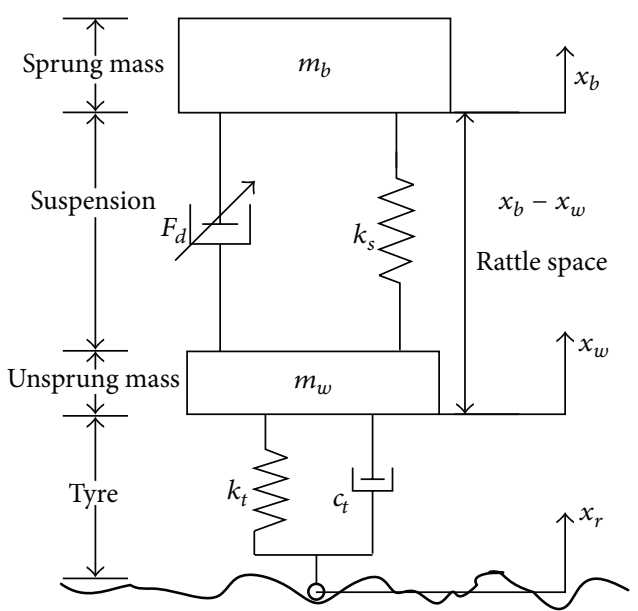

(b)

FIGURE 1: Ideal and equivalent models. (a) Ideal hybrid suspension system, (b) equivalent hybrid suspension system.

where

$$
\begin{aligned}
A= & m_{w} m_{b} s^{4}+\left(c_{\mathrm{grd}} m_{b}+c_{\mathrm{sky}} m_{w}+c_{t} m_{b}\right) s^{3} \\
& +\left(m_{w} k_{s}+m_{b} k_{s}+m_{b} k_{t}+c_{\mathrm{sky}} c_{t}\right) s^{2} \\
& +\left(c_{\mathrm{sky}} k_{t}+c_{t} k_{s}\right) s+k_{t} k_{s}, \\
D= & -m_{b} m_{w} s^{4}-\left(c_{\mathrm{grd}} m_{b}+c_{\mathrm{sky}} m_{w}\right) s^{3} \\
& -\left(m_{b} k_{s}+m_{w} k_{s}\right) s^{2} .
\end{aligned}
$$

For a stationary and ergodic stochastic process, the variance of a random variable can be described as [34]

$$
\sigma_{p}^{2}=\frac{1}{2 \pi} \int_{-\infty}^{\infty} S_{p}(\omega) d \omega .
$$

The Power Spectral Density (PSD) of the output can be computed as

$$
S_{p}(\omega)=\left|H(j \omega)_{p \sim x_{r}}\right|^{2} S_{x_{r}}(j \omega)
$$

where $p=1,2,3,4$ represent the four translation functions shown in (11).

Previous research has shown that if $S_{p}(\omega)$ can be expressed as (15), then an analytical solution for $\sigma_{p}^{2}$ exists [35]:

$$
S_{p}(\omega)=\frac{N_{k-1}(j \omega) N_{k-1}(-j \omega)}{D_{k}(j \omega) D_{k}(-j \omega)},
$$

where $D_{k}$ is a polynomial of degree $k$ and $N_{k-1}$ is a polynomial of degree $k-1 . D_{k}$ and $N_{k-1}$ can be expressed as

$$
\begin{gathered}
D_{k}(j \omega)=d_{k}(j \omega)^{k}+d_{k-1}(j \omega)^{k-1}+\cdots+d_{0}, \\
N_{k-1}(j \omega)=n_{k-1}(j \omega)^{k-1}+n_{k-2}(j \omega)^{k-2}+\cdots+n_{0} .
\end{gathered}
$$

In order to express $S_{p}(\omega)$ in the form of (15), according to (2), the PSD of the road input and translation functions can be expressed as

$$
\begin{aligned}
G_{q}(f) & =\frac{a v \rho^{2}}{\pi\left[(a v)^{2}+f^{2}\right]}, \\
& \longrightarrow S_{x_{r}}(j \omega)=\frac{a v \rho^{2}}{\pi} \frac{1}{(a v+j \omega)} \frac{1}{(a v-j \omega)} .
\end{aligned}
$$

The transformation function of (11) can also be expressed as

$$
\left|H(j \omega)_{p \sim x_{r}}\right|^{2}=H(j \omega)_{p \sim x_{r}} H(-j \omega)_{p \sim x_{r}} .
$$

For this problem, the value of $k$ can be easily calculated: $k=5$. The analytical solution of $\sigma_{p}^{2}$ can hence be expressed as [16]

$$
=\frac{\left(n_{4}^{2} c_{m 0}+\left(n_{3}^{2}-2 n_{2} n_{4}\right) c_{m 1}+n_{m 0} c_{m 2}+\left(n_{1}^{2}-2 n_{0} n_{2}\right) c_{m 3}+n_{0}^{2} c_{m 4}\right)}{2 d_{0}\left(d_{1} c_{m 4}-d_{3} c_{m 3}+d_{5} c_{m 2}\right)},
$$

where $n_{0}, \ldots, n_{4}$ and $d_{0}, \ldots, d_{5}$ stand for the numerator and denominator items shown in (16) and $n_{m 0}, c_{m 0}, \ldots, c_{m 4}$ represent the intermediate variables shown below:

$$
\begin{aligned}
& n_{m 0}=n_{2}^{2}-2 n_{1} n_{3}+2 n_{0} n_{4}, \\
& c_{m 0}=\frac{d_{3} c_{m 1}-d_{1} c_{m 2}}{d_{5}}, \\
& c_{m 1}=-d_{0} d_{3}+d_{1} d_{2}, \\
& c_{m 2}=-d_{0} d_{5}+d_{1} d_{4}, \\
& c_{m 3}=\frac{d_{2} c_{m 2}-d_{4} c_{m 1}}{d_{0}}, \\
& c_{m 4}=\frac{d_{2} c_{m 3}-d_{4} c_{m 2}}{d_{0}} .
\end{aligned}
$$


In this manner, the analytical expressions for determining the acceleration of sprung mass, the tyre force, and the rattle space with respect to road excitation are derived. Due to space limitations, the detailed expressions cannot be represented here. Similar deduction of the analytical expressions for passive and skyhook control has been successfully applied by Valášek et al. [16] and Hurmuzlu and Nwokah [17].

\section{Damping Coefficients Calculation}

In this section, a brief introduction of MOOP (Multiobjective Optimization Problems) is presented, and the calculation of damping coefficients for different road levels is described.

Optimization problems are of great importance in engineering design, decision making, and experimentation. When an optimization problem includes more than one objective function, it may be treated as MOOP.

Multiple different methods are available for solving MOOP, such as direct methods and gradient-based methods [36]. These classical methods do however have some limitations in common [24]:

(1) The initial solutions for the objective functions determine their convergence to the optimal solutions.

(2) An algorithm derived by these methods may be limited in certain scope and unable to be used to effectively solve other types of problems.

(3) These classical methods can only obtain one solution per iteration.

To better understand the MOOP, the concept of "Pareto optimal solutions" is illustrated here. The solutions in the Pareto optimal solution set possess the property that there are no other feasible solutions that can decrease one criterion without causing an increase in any other criterions [37]. To be specific, the solution obtained by classical methods within one iteration is one solution in the Pareto optimal solution set. Evolutionary algorithms have thus been proposed to overcome the above limitations [24]. Genetic algorithm is one such that algorithm starts from random initial solutions, applying operations of selection, crossover, and mutation, to obtain Pareto optimal solutions. The criterion for selection is the fitness function, which is always set as the objective functions.

Since the analytical expressions for ride comfort, road handling, and rattle space have been derived, the choice of damping coefficients transforms into MOOP. In this paper, the NSGA-II method is applied to solve this problem [23]. The flow chart of NSGA-II is shown in Figure 2.

The NSGA-II procedure can be briefly described as follows:

(1) Initialise the population. The parameters of NSGA-II are chosen at this step, such as the number of elites and the population size.

(2) Generate solutions. Random initial solutions are generated at this step.

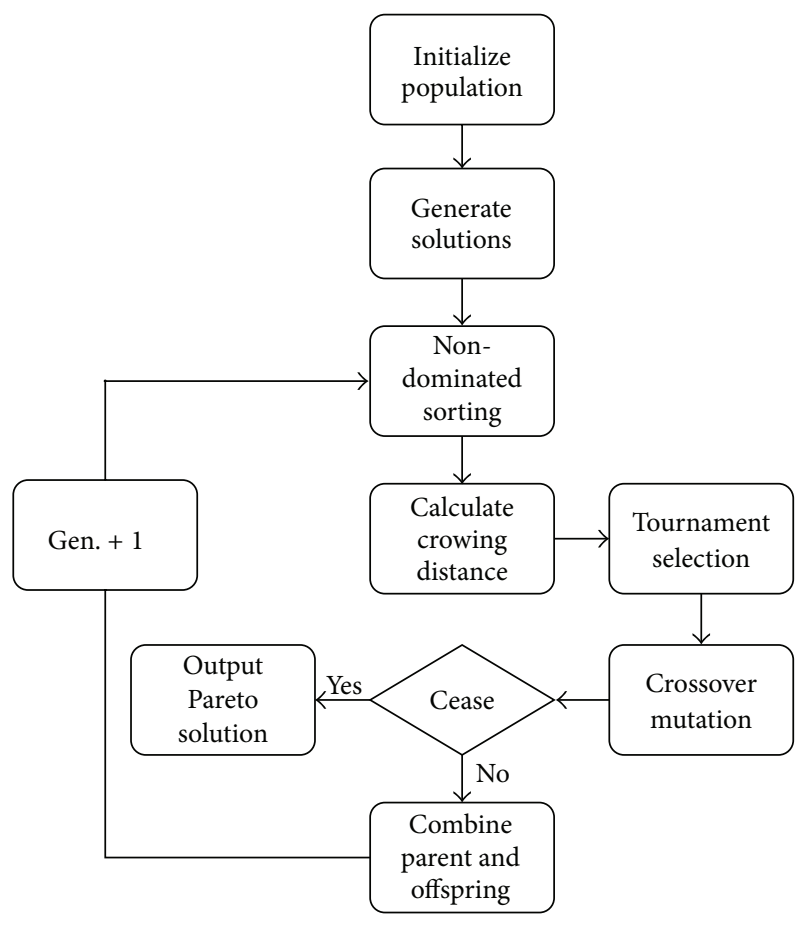

FIgURE 2: Flow chart of NSGA-II.

(3) Achieve nondominated sorting. The values of the fitness function are calculated for each solution, and different fronts are assigned after comparison.

(4) Calculate crowding distance. In order to ensure the diversity of the solution set, crowding distances must be calculated, and solutions with higher crowding distance must have a greater probability of being selected.

(5) For selection, crossover, and mutation, new solutions are generated after these three steps.

(6) Combine parent and offspring. A combination of both the parent and the offspring generations is formed, and the best solutions with a predefined population size are chosen.

(7) Cease. When the number of generations or the variation of the fitness function reaches a predefined value, the procedure stops and Pareto optimal solutions are generated.

The MOOP dealt with in this paper can thus be expressed as follows:

$$
\begin{aligned}
\min & f_{1}\left(c_{\text {sky }}, c_{\text {grd }}\right)=\sigma_{\ddot{x}_{b}}^{2}, \\
& f_{2}\left(c_{\text {sky }}, c_{\text {grd }}\right)=\sigma_{f_{D}}^{2}, \\
\text { subject to } & 6 \cdot\left|\sigma_{x_{b}-x_{w}}\right| \leq \lim \left(x_{b}-x_{w}\right), \\
& 500(\mathrm{Ns} / \mathrm{m}) \leq c_{\text {sky }} \leq 5000(\mathrm{Ns} / \mathrm{m}), \\
& 500(\mathrm{Ns} / \mathrm{m}) \leq c_{\text {grd }} \leq 5000(\mathrm{Ns} / \mathrm{m}),
\end{aligned}
$$




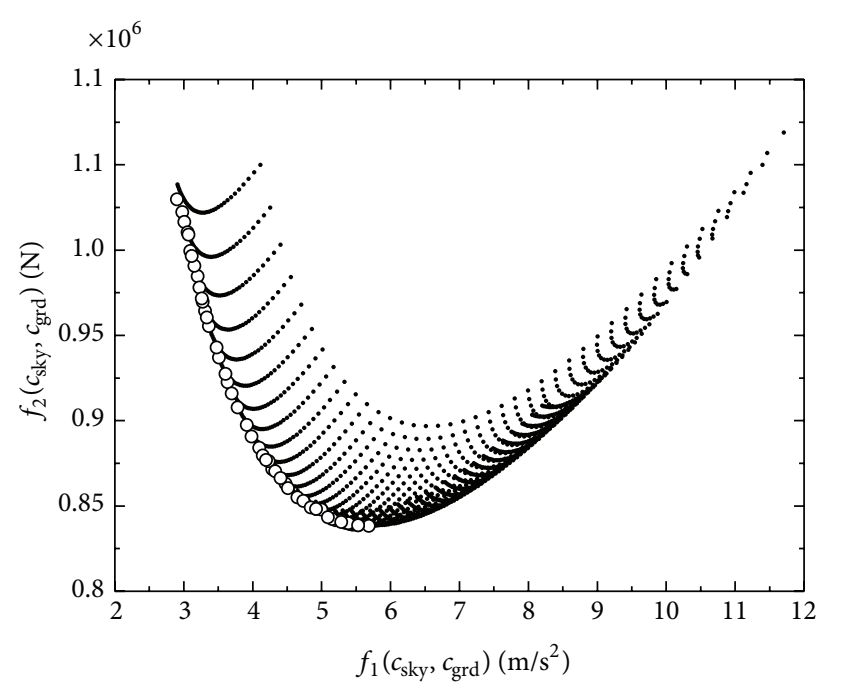

- Objective function value

- Pareto optimal solution

FIGURE 3: Objective space and Pareto optimal solutions for road level $\mathrm{D}, 40 \mathrm{~km} / \mathrm{h}$.

where $\sigma_{\ddot{x}_{b}}^{2}$ and $\sigma_{f_{D}}^{2}$ stand for the variances of the sprung mass acceleration and tyre force, respectively, as derived in Section 3 and $\lim \left(x_{b}-x_{w}\right)$ represents the rattle space constraint, the value of which is taken as $120 \mathrm{~mm}$ in this paper and it assumes that the bounce and rebound limit are equal in simulation. It should be noted that $f_{1}$ and $f_{2}$ are functions of both road level and velocity. In order to illustrate the properties of Pareto optimal solutions and the choice of control gains, the MOOP shown in (21) is solved for road level $\mathrm{D}$, with a velocity of $40 \mathrm{~km} / \mathrm{h}$ as an example. The parameters of NSGA-II are set as follows: population size is 100 , the optimal solution number in the first Pareto front is 50 , and the maximum generation is 200 . The Pareto optimal solution set and objective area are shown in Figure 3. It can be seen that the Pareto optimal solution set, which is represented as circles, is located at the bottom left of the objective area. These circles are believed to be equal solutions if we do not specify the orientation of the suspension system. The results in Figure 3 show that the Pareto optimal solutions are widely distributed along the Pareto optimal front, which means that although the locations of initial solutions and the corresponding final solutions are random, the difference between solutions for different runs is still acceptable in terms of the value of the objective function. For different road level and velocity, the Pareto optimal solutions can be calculated off-line and prestored in the controller for further application.

\section{Road Estimation}

According to the analysis conducted in Section 4, both $f_{1}$ and $f_{2}$ are functions of both road level and velocity. The velocity of a vehicle can be obtained through the CAN bus; however, it should be noted that there might be message delays when there is a message collision during the application of CAN bus. Since the road estimation interval is $0.5 \mathrm{~s}$, we assume that the velocity of vehicle is constant during this interval. The road level must be updated continuously during driving in order to successfully realise suspension control. In this section, a review of road estimation techniques is presented at first, and a new method for road estimation and classification is then introduced.

During the past few decades, a significant number of studies have been conducted on road estimation and reproduction. Previous research can be divided into three categories:

(1) Direct measurement. This method generally utilises profilometers to measure the amplitude of the road profile. It has been proven to be very precise; however, the structure of the instruments restricts its application in commercial vehicles $[38,39]$.

(2) Road estimation based on vehicle response. This method utilises multiple different sensors, such as acceleration sensors for sprung or unsprung mass and LVDT for rattle space, along with a system model to estimate the road profile. This method is the most popular and has attracted much research attention [40-42].

(3) Noncontact measurement. This method uses laser (light, ultrasonic) transceivers to measure the road profile in a relatively accurate manner; however, the cost of the instruments and kinds of complex accessory equipment limit its business application [43].

This paper requires the road estimation method used to interoperate effectively with the suspension system control, in order to ensure suspension system performance. This introduces two general requirements that must be fulfilled:

(1) Accuracy. As different control gains are assigned to different road levels (the principles on which gain choice is based are shown in the simulation section), the estimated road level needs to be accurate; otherwise degradation of road handling may occur during poor road conditions, which may cause braking and steering force reduction or even lead to the vehicle system becoming out of control.

(2) Real time. Since the level of the road changes randomly, the proposed estimation method is required to be able to respond to changes in the road level without large time lag.

Because of this, rather than utilising the conventional methods mentioned above, a new method for road level estimation is proposed involving two steps. Firstly, the amplitude of the road profile is estimated according to the vehicle system response, and then a wavelet transform is applied and the road level is classified based on the detail components (high frequency sections) calculated by the wavelet transform.

The basic methodology for road profile estimation can be described as follows: reverse the vehicle suspension system, and apply the system response to estimate the road profile in 


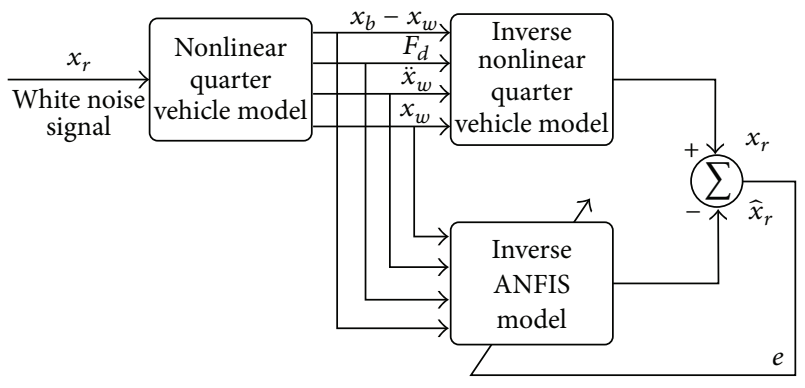

FIGURE 4: Structure of road estimation with ANFIS.

the time domain with an inverse ANFIS model. To be specific, according to (10), the road input can be expressed as

$$
x_{r}=f\left(\ddot{x}_{w}, x_{w},\left(x_{w}-x_{b}\right), F_{d}\right),
$$

which means that the road profile can be expressed as a function of four items: acceleration of unsprung mass, displacement of unsprung mass, rattle space, and the control force. Once the values of these four items are obtained, we can calculate the road profile with the function shown in (22). In this paper, the function is replaced by an inverse ANFIS model, and after proper training the road profile is calculated according to the well-trained inverse ANFIS model. It should be noted that it is important to ensure the completeness of the training signal; otherwise large identification errors may appear. In this case, a white noise signal with amplitude of $0.25 \mathrm{~m}$ and an upper cut-off frequency of $30 \mathrm{~Hz}$ is applied to train the inverse ANFIS model [25]. The structure of the inverse ANFIS model training process is shown in Figure 4. For more information about road profile estimation in the time domain with ANFIS, readers are invited to refer to [25].

After the estimated road profile $\widehat{x}_{r}$ is derived, wavelet transform is used for $\widehat{x}_{r}$ and the value of the RMS (root mean square) of the detail components, that is, the high frequency section of road profile, is applied for classification. A wavelet transform based method is utilised for the following reasons:

(1) Since the excitation energy will rise as the road level increases, a higher level road will always be associated with a PSD higher amplitude across the whole frequency domain.

(2) As the slope of the road PSD is negative according to its ISO definition as shown in (1), the PSD amplitude of the lower frequency section must be much larger than that of the high frequency section. In order to fulfil the real-time requirement mentioned earlier, the slowly changing components of the road, that is, the lower frequency part, must be removed or reduced.

It should be noted that wavelet transform is not the only possible choice for road classification. Several other methods for time-frequency domain analysis can also be applied, such as EMD (empirical mode decomposition) or a simple high pass filter. All three methods have been tested for this problem, with the results showing that both the wavelet transform and the EMD (1st order IMF) methods have similar accuracy. Due to phase shifting and the difficulty of choosing the upper cut-off frequency, the high pass filter method produces inaccurate results and hence is not recommended. In the following simulation section, wavelet transform is chosen as the classification method and the wavelet base is chosen as "db3."

\section{State Observer Design}

According to the analysis in Section 5, in order to estimate the road profile, it is necessary to know the value of four variables: the acceleration of the unsprung mass, displacement of the unsprung mass, rattle space, and control force. The acceleration of the unsprung mass can be measured directly with an acceleration sensor, and the control force can be calculated according to the control strategy shown in Section 3. The rattle space can be measured with a LVDT embedded in the damper; however, as the sensor is not connected directly to the sprung and unsprung mass, the difference between the measured and actual values of the rattle space cannot be ignored. As indicated in previous research, the displacement of the unsprung mass can be calculated by a band pass filter [2]. Due to the existence of the DC offset and phase shift of the filter, it is difficult to design and apply such a filter in practice [22]. A Kalman filter is hence designed to observe the rattle space and displacement of the unsprung mass.

The discrete state space model for the quarter vehicle can be written as

$$
\begin{aligned}
x_{k+1} & =A x_{k}+B u_{k}+G r_{k}+F w_{k}, \\
y_{k} & =C x_{k}+D u_{k}+v_{k},
\end{aligned}
$$

where $u$ is the control force, $r$ is the road disturbance, $w$ is the road velocity, and $v$ is the sensor noise.

The system state vector is chosen as

$$
\vec{x}=\left[x_{b}, \dot{x}_{b}, x_{w}, \dot{x}_{w}\right]^{T} .
$$

The system output vector is

$$
\vec{y}=\left[\ddot{x}_{b}, \ddot{x}_{w}\right]^{T} .
$$

The system matrixes are

$$
A=E+\Delta t \cdot\left[\begin{array}{cccc}
0 & 1 & 0 & 0 \\
-\frac{k_{s}}{m_{b}} & 0 & \frac{k_{s}}{m_{b}} & 0 \\
0 & 0 & 0 & 1 \\
\frac{k_{s}}{m_{w}} & 0 & -\frac{k_{t}+k_{s}}{m_{w}} & -\frac{c_{t}}{m_{w}}
\end{array}\right],
$$

$$
B=\Delta t \cdot\left[\begin{array}{c}
0 \\
-\frac{1}{m_{b}} \\
0 \\
\frac{1}{m_{w}}
\end{array}\right]
$$




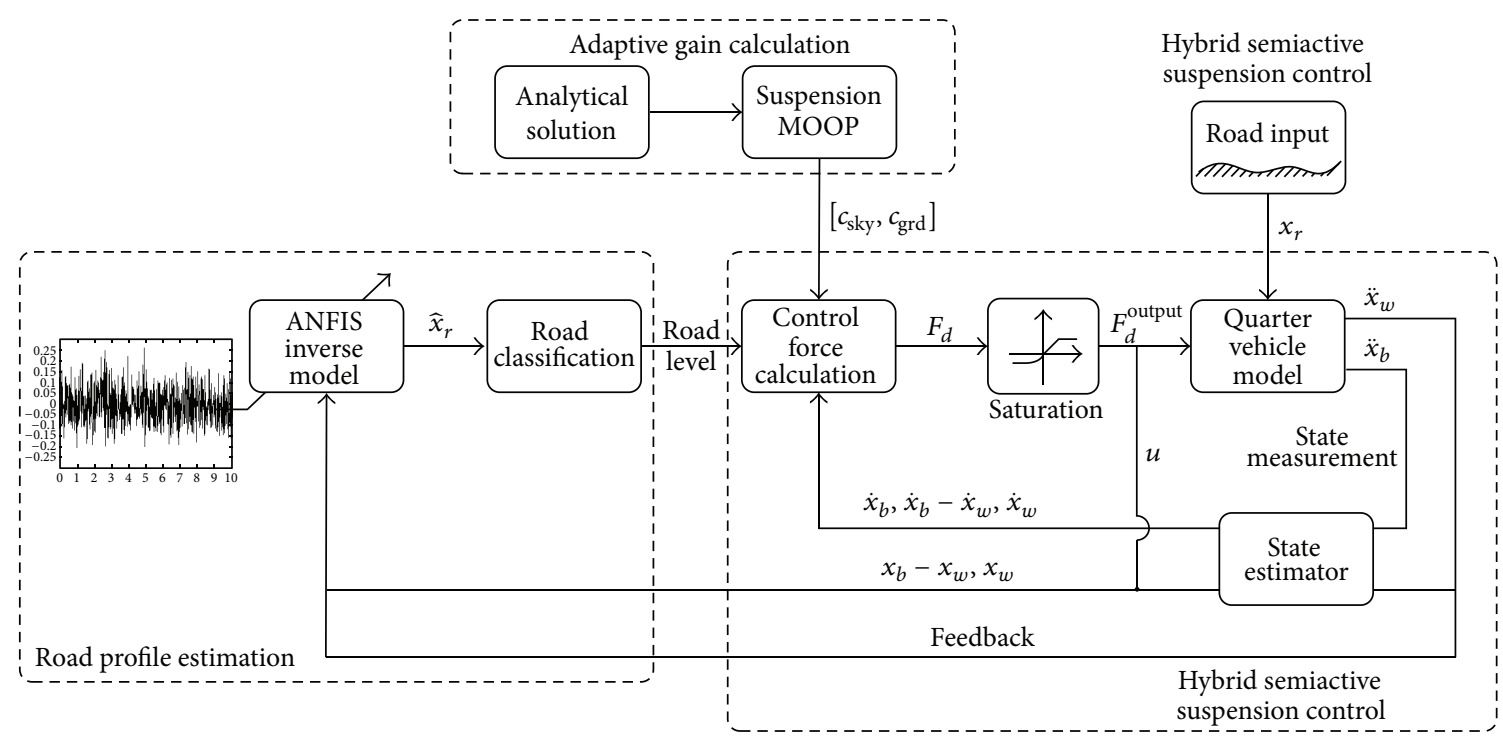

FIGURE 5: Structure of road estimation based hybrid control strategy.

$$
\begin{aligned}
& G=\Delta t \cdot\left[\begin{array}{c}
0 \\
0 \\
0 \\
\frac{k_{t}}{m_{w}}
\end{array}\right] \text {, } \\
& F=\Delta t \cdot\left[\begin{array}{c}
0 \\
0 \\
0 \\
\frac{c_{t}}{m_{w}}
\end{array}\right] \text {, } \\
& C=\left[\begin{array}{cccc}
-\frac{k_{s}}{m_{b}} & 0 & \frac{k_{s}}{m_{b}} & 0 \\
\frac{k_{s}}{m_{w}} & 0 & -\frac{k_{t}}{m_{w}} & -\frac{c_{t}}{m_{w}}
\end{array}\right] \text {, } \\
& D=\left[\begin{array}{c}
-\frac{1}{m_{b}} \\
\frac{1}{m_{w}}
\end{array}\right],
\end{aligned}
$$

where $E$ is the identity matrix and the $\Delta t$ is the sampling interval. The procedure can be expressed as follows.

Step 1. Time update is as follows:

$$
\begin{aligned}
& \hat{x}_{k}^{-}=A \widehat{x}_{k-1}+B u_{k-1}, \\
& P_{k}^{-}=A P_{k-1} A^{T}+Q .
\end{aligned}
$$

Step 2. Measurement update is as follows:

$$
K_{k}=P_{k}^{-} C^{T}\left(C P_{k}^{-} C^{T}+R\right)^{-1},
$$

$$
\begin{aligned}
& \widehat{x}_{k}=\widehat{x}_{k}^{-}+K_{k}\left[y_{k}-\left(C \widehat{x}_{k}^{-}+D u_{k}\right)\right], \\
& P_{k}=\left(I-K_{k} C\right) P_{k}^{-},
\end{aligned}
$$

where $R$ is the measurement noise covariance matrix, $Q$ is the process noise covariance matrix, $P$ is the estimate error covariance matrix, $K$ is the Kalman gain, and $\widehat{x}_{k}^{-}$and $\widehat{x}_{k}$ are priori and posteriori state estimates, respectively, at step $k$. Both $P$ and $K$ will change iteratively and ultimately converge to a constant value.

\section{Simulation Results}

In this section, the system structure of the proposed control strategy is introduced, and a road profile with five different levels is utilised to validate the control strategy and road estimation method. An analysis of the simulation results is then provided.

The block diagram for the system structure is shown in Figure 5.

As can be seen from Figure 5, the proposed strategy involves three elements: calculation of adaptive control gains, road profile estimation, and hybrid suspension control. The functions and relationship between these three elements may be described as follows.

Adaptive gain calculation utilises the analytical expressions shown in Section 3 to calculate the damping coefficients combination $\left[c_{\text {sky }}, c_{\text {grd }}\right]$ for different road levels utilising the MOOP described in Section 4. The results are then stored for control force calculation.

Road profile estimation corresponds to Section 5. This involves estimation of the road profile in the time domain by utilising the inverse ANFIS model, with the results of a wavelet transform for the estimated road unevenness $\widehat{x}_{r}$ being applied for classification. The obtained road level is then sent to the hybrid control stage. 
TABLE 2: Parameters of quarter vehicle.

\begin{tabular}{llc}
\hline$m_{\mathrm{b}}$ & Sprung mass & $256 \mathrm{~kg}$ \\
$m_{\mathrm{w}}$ & Unsprung mass & $30 \mathrm{~kg}$ \\
$k_{\mathrm{t}}$ & Tyre spring stiffness & $186000 \mathrm{~N} / \mathrm{m}$ \\
$k_{\mathrm{s}}$ & Suspension spring stiffness & $22000 \mathrm{~N} / \mathrm{m}$ \\
$c_{\mathrm{p}}$ & Passive damping coefficient & $1100 \mathrm{Ns} / \mathrm{m}$ \\
$c_{\text {sky }}$ & Skyhook damping coefficient range & $500-5000 \mathrm{Ns} / \mathrm{m}$ \\
$c_{\text {grd }}$ & Ground damping coefficient range & $500-5000 \mathrm{Ns} / \mathrm{m}$ \\
$c_{\mathrm{t}}$ & Tyre damping coefficient & $0 \mathrm{Ns} / \mathrm{m}$ \\
$c_{\text {min }}$ & Hybrid minimum damping coefficient & $200 \mathrm{Ns} / \mathrm{m}$ \\
\hline
\end{tabular}

The hybrid suspension control stage corresponds to Section 3. The ideal control force is calculated according to the road level and control gain, and this ideal control force $F_{d}$ must then be compared with the limitation of the damping force, that is, the saturation. The actual control force $F_{d}^{\text {output }}$ derived from this is next applied in the quarter vehicle model. The responses of the model $\left[\ddot{x}_{b}, \ddot{x}_{w}\right]$ are used to observe the unknown variables, and the observed variables are applied in the inverse ANFIS model and control force calculation blocks for estimating the road profile and calculating the control force, respectively.

In order to evaluate the performance of the proposed control strategy and road classification method, a random road profile is generated, and its performance is compared with a passive suspension system. For the sake of comparison and analysis, unless otherwise stated, the velocity is taken as $40 \mathrm{~km} / \mathrm{h}$ and the sample frequency is $1000 \mathrm{~Hz}$.

The parameters of the passive quarter vehicle model are given in Table 2.

A simple calculation reveals that the natural frequency of the sprung mass is $f_{1}=1.47 \mathrm{~Hz}$, the natural frequency of the unsprung mass is $f_{2}=13.25 \mathrm{~Hz}$, and the damping ratio for passive system is $\xi=0.23$. These parameters confirm the validity of the referenced passive quarter model.

Since all the Pareto optimal solutions in Figure 3 are assumed to be equal (as stated in Section 4), the next step is to choose control weights for the different road levels, with the choice of control weights directly determining the damping coefficients of the hybrid control. The choice of control weights is subjective; however, an effective general principle upon which this choice may be based is as follows: as stated in the introduction part, the road handling can be interpreted as the force between tyre and road surface. Since higher road level means higher input energy, which will lead to higher tyre force variation, we need to assign greater weighting to road handling aspect for worse roads to obtain better braking and steering ability; as for good roads, however, a larger weighting of ride comfort is desirable in order to enhance passenger experience. Under this principle, the control weights and corresponding damping coefficients are presented in Table 3. In order to save time and increase efficiency, the damping coefficients for different road level can be precalculated and saved in the controller.

The road excitation used for the simulation is shown in Figure 6(a).
TABLE 3: Control weights and damping coefficients for different road levels.

\begin{tabular}{lcc}
\hline Road level & Weights $\left[w_{\text {acc }}, w_{\text {tire }}\right]$ & {$\left[c_{\text {sky }}, c_{\text {grd }}\right]$} \\
\hline Very good $(A, B)$ & {$[0.8,0.2]$} & {$[3720,620]$} \\
Good $(C, D)$ & {$[0.6,0.4]$} & {$[3265,950]$} \\
Poor $(E, F)$ & {$[0.4,0.6]$} & {$[3030,1390]$} \\
Very poor $(\mathrm{G}, \mathrm{H})$ & {$[0.2,0.8]$} & {$[2750,1680]$} \\
\hline
\end{tabular}

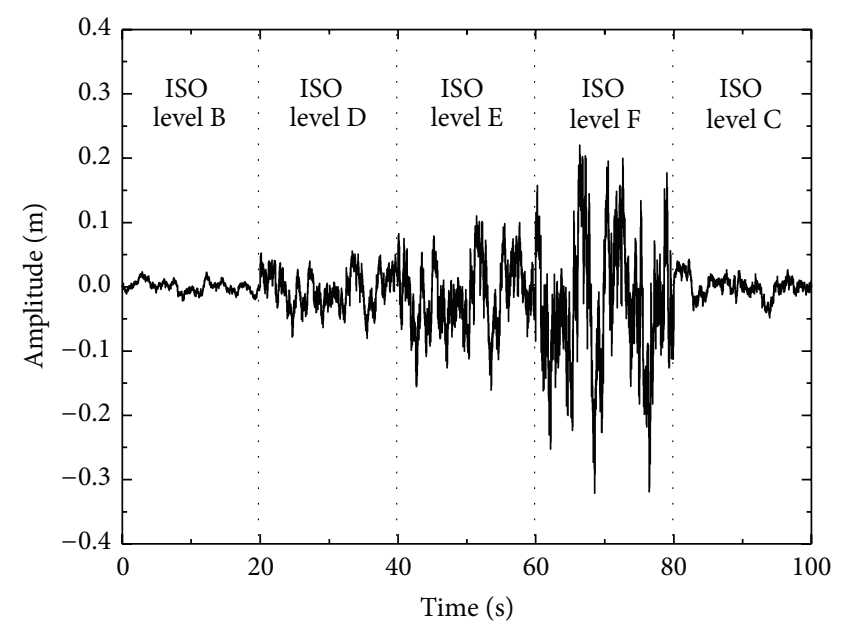

(a)

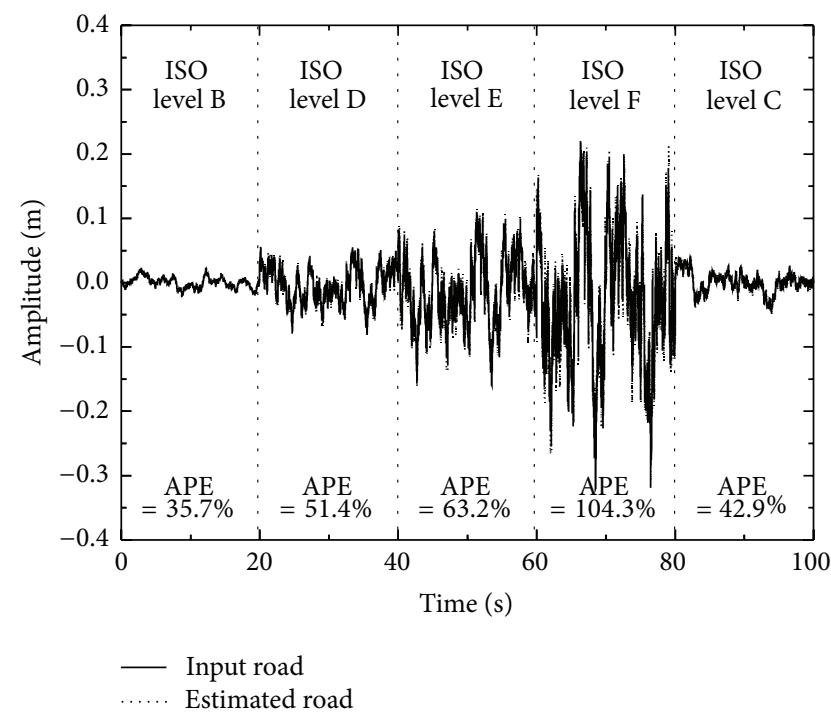

(b)

FIGURE 6: Input road profile and its estimation. (a) Road excitation in time domain, (b) comparison for actual input and estimated road profile.

It can be seen that the road profile is composed of five different road levels: levels B, D, E, F, and C, in successive order. For the purpose of analysis, two assumptions are applied here:

(1) During the driving process, the velocity of the vehicle remains unchanged. 


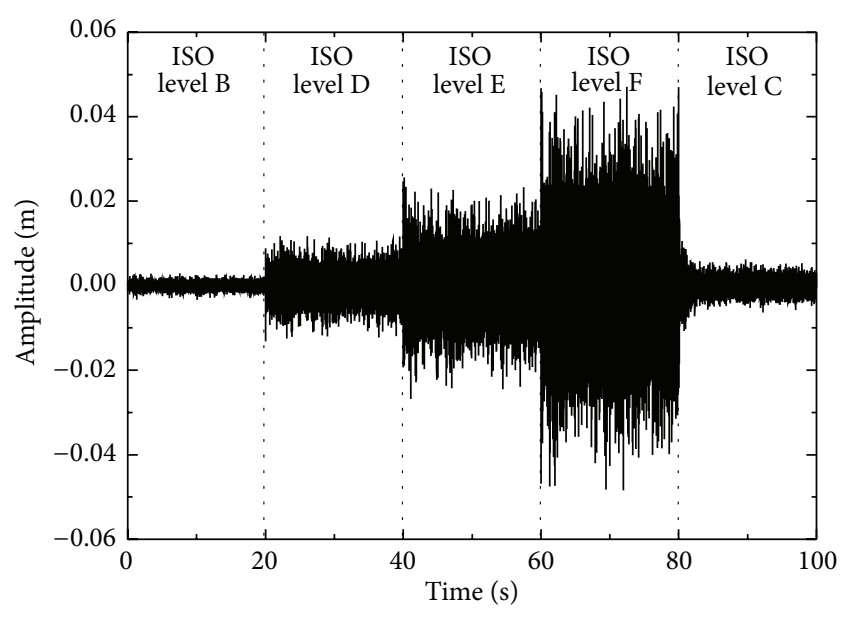

FIGURE 7: Detail components for estimated road profile.

(2) The road level remains unchanged within every 20 seconds.

With the proposed road profile estimation method and the variables estimated with the Kalman method as described in Sections 5 and 6, the road profile can be estimated across the time domain. The results of this are shown in Figure 6(b). In order to evaluate the performance of the proposed method, the index named APE (Average Percent Error) is utilised [44]:

$$
\mathrm{APE}=\frac{1}{P} \sum_{i=1}^{P} \frac{|T(i)-O(i)|}{|T(i)|} \times 100 \%,
$$

where $P$ is the amount of data and $T(i)$ and $O(i)$ are the $i$ th actual output and calculated output values, respectively.

The results show that the proposed inversed ANFIS model can estimate the road profile with a relatively high degree of precision and that APE increases as road level quality decreases. Higher input amplitudes are associated with larger estimation errors, and for the road input level F, the APE value reaches $104.3 \%$, much higher than that for the other levels. This phenomenon can be interpreted as a result of the excitation amplitude reaching or even exceeding $0.25 \mathrm{~m}$, which is the maximum amplitude of the training white noise signal, which would lead to the appearance of large local errors, increasing the average APE of the whole time period. This is why the training signal must be comprehensive, covering the entire time and frequency domain

Utilising the classification method proposed in Section 5, the road classification results are presented below. The result of wavelet transform is shown in Figure 7, and the original and estimated road classification results are compared in Figure 8.

Figure 7 clearly shows the changes in amplitude across different road levels. Compared to the original road profiles shown in Figure 6(a), Figure 8 shows that the high frequency section is in the dominant position, facilitating the use of a high frequency based classification method.

In Figure 8, we calculate and compare the RMS of both the actual and the estimated road profiles, and the calculation

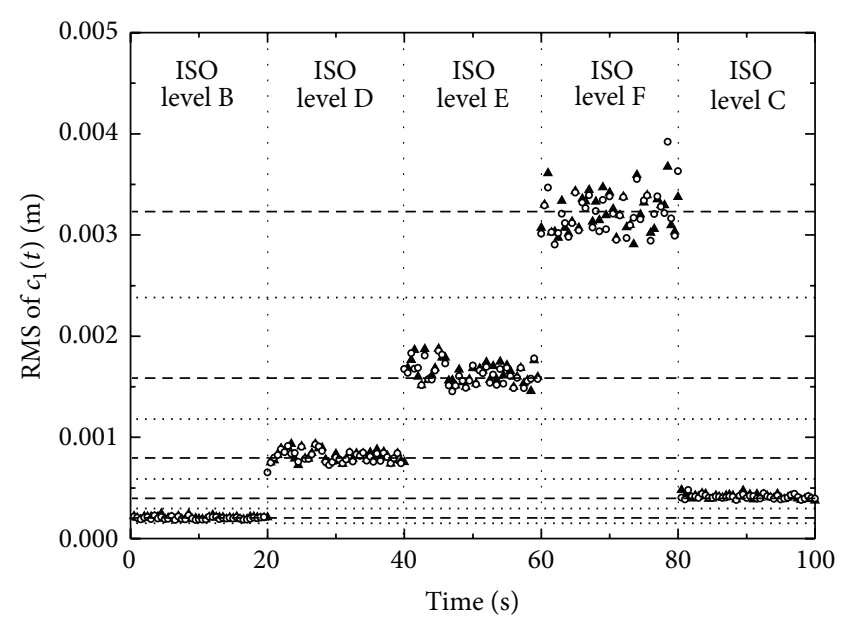

- RMS of estimated road - - RMS of lower limit ○ RMS of input road $\quad \ldots$ RMS of standard level

FIGURE 8: Classification of road profile with detail components.

interval is chosen to be $500 \mathrm{~ms}$. It should be noted that the choice of calculation interval is arbitrary; in this paper, $500 \mathrm{~ms}$ is sufficient to satisfy the real-time requirement since we assume that the road level will not frequently change within very short time interval, which also correspond to our basic knowledge. In this case, there are 40 points for each level and 200 points in total for the whole time period. The solid triangles represent the RMS of the estimated road and the circles represent the RMS of the actual input road, while the long dashes and short dashes represent the standard and lower bounds, respectively, for each road level. Although some errors are apparent during the estimation process, as shown in Figure 6(b), the RMS of the estimated roads is still located within the same range as the correct road level, meaning that accuracy requirements are satisfied. It can also be seen that the estimated RMS converges quite rapidly to fit new road levels, meaning that the delays in the classification procedure are negligible with an interval of $500 \mathrm{~ms}$. This demonstrates that the proposed method meets real-time requirements. It should be noted that the average RMS values and lower limits for the different road levels are just points of reference used for classification purposes. In order to derive the reference points, each road level is generated 100 seconds in advance, and the RMS values are calculated utilising the detail part of signal for every $500 \mathrm{~ms}$. The standard and lower limit values (reference points) are the mean values of these 200 points.

After road level classification, the damping coefficients can be altered adaptively according to the road level and the control weights combinations shown in Table 3. In order to evaluate the performance of the proposed hybrid control algorithm, both ride comfort and road handling (the acceleration of sprung mass and the tyre force, resp.) are compared in time and frequency domain, with the results shown in Table 4 and Figures 9 and 10.

Table 4 shows that both sprung mass acceleration and tyre force increase as the road level increases, in both the 
TABLE 4: Comparison of ride comfort and road handling.

\begin{tabular}{lcccc}
\hline \multirow{2}{*}{$\begin{array}{l}\text { Road } \\
\text { level }\end{array}$} & \multicolumn{2}{c}{$\begin{array}{c}\text { RMS of sprung mass } \\
\text { acceleration }\left(\mathrm{m} / \mathrm{s}^{2}\right)\end{array}$} & \multicolumn{2}{c}{ RMS of tyre force $(\mathrm{N})$} \\
& Passive & Semiactive & Passive & Semiactive \\
\hline B & 0.561 & 0.479 & 261.2 & 277.8 \\
D & 2.245 & 2.186 & 1044.5 & 1046.8 \\
E & 4.491 & 5.049 & 2088.9 & 1989.1 \\
F & 8.982 & 10.131 & 4177.9 & 3973.3 \\
C & 1.123 & 1.093 & 522.2 & 523.3 \\
\hline
\end{tabular}

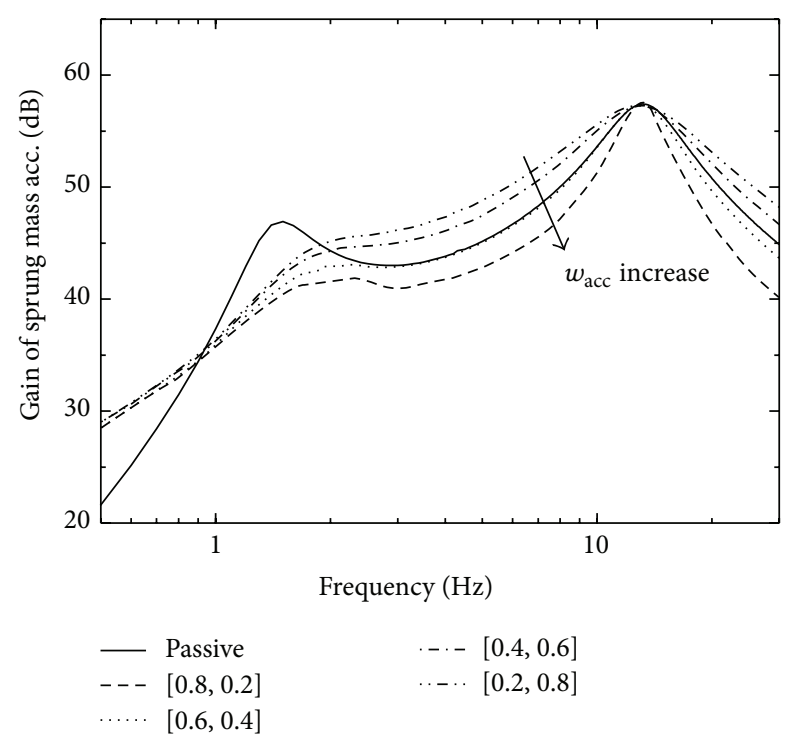

FIGURE 9: Comparison of frequency responses of $\ddot{x}_{b} / x_{r}$ for different control weights.

passive and the semiactive system. From road levels from B to $\mathrm{F}$, the passive system's RMS of sprung mass acceleration increases from $0.561 \mathrm{~m} / \mathrm{s}^{2}$ to $8.982 \mathrm{~m} / \mathrm{s}^{2}$, while the value of the semiactive system changes from $0.479 \mathrm{~m} / \mathrm{s}^{2}$ to $10.131 \mathrm{~m} / \mathrm{s}^{2}$. This shows that the semiactive suspension system with the proposed algorithm can better isolate the vibration for the sprung mass on good road conditions; however, for poor road excitation, the ride comfort performance degrades. In terms of road handling, the tyre force RMS for the passive system increases from $261.2 \mathrm{~N}$ to $4177.9 \mathrm{~N}$, while that of the semiactive system varies from $277.8 \mathrm{~N}$ to $3973.3 \mathrm{~N}$, which may be interpreted as demonstrating better road handling performance for poor roads and worse performance for good roads.

Figure 9 shows that as the road quality becomes worse, the acceleration response of sprung mass for both sprung mass natural frequency $(1.47 \mathrm{~Hz})$ and human sensitive frequency range $(4 \sim 8 \mathrm{~Hz})$ keeps increasing. It should be noted that all four control weights combinations can better isolate vibration at about $1.5 \mathrm{~Hz}$ than passive system, and only control weights combinations for road levels A and B can improve the ride comfort for $4 \sim 8 \mathrm{~Hz}$, which result in the degradation of RMS for road levels $E$ and $F$ as shown in Table 4. Figure 10 demonstrates that, with the increasing of

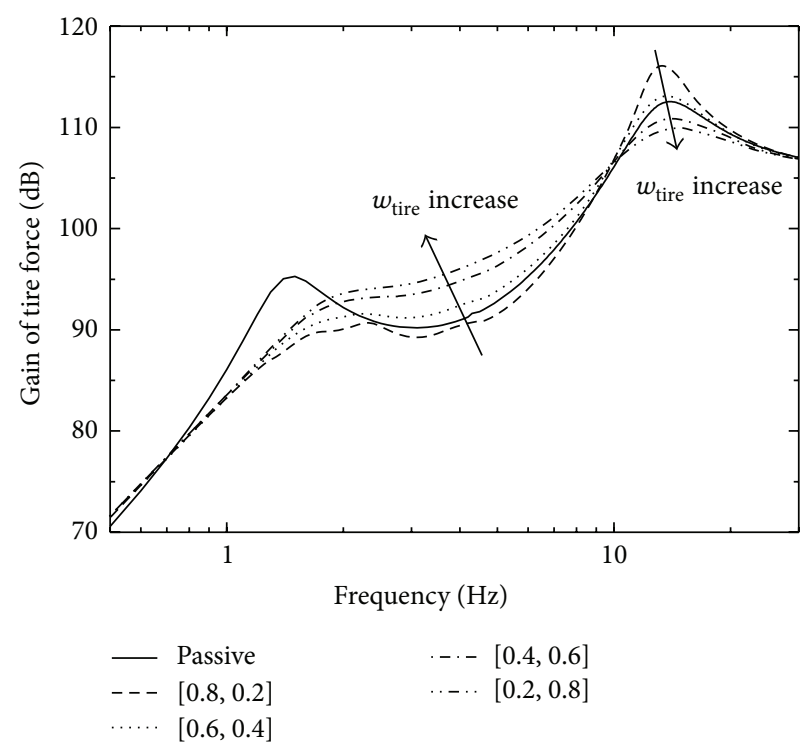

FIGURE 10: Comparison of frequency responses of $f_{D} / x_{r}$ for different control weights.

$w_{\text {tire }}$, the hybrid semiactive suspension system can effectually depress the response around unsprung mass natural frequency for "poor" and "very poor" road conditions; however, the response of these two control weights combinations for $4 \sim 8 \mathrm{~Hz}$ is worse than that of passive system, leading to the smaller improvement of road handling for " $E$ " and " $F$ " levels.

From the above discussion, we can see that, with the degradation of road quality, the semiactive suspension system with the hybrid control algorithm changes from being ride comfort oriented to being road handling oriented. According to the results shown in Table 3 , it can be seen that as the weighting given to road handling increases the damping coefficient of $c_{\text {sky }}$ will decrease while that of $c_{\text {grd }}$ will increase. This corresponds to the basic operation of vibration control: by increasing the damping coefficient, the vibration of the connected mass can be reduced.

It should also be noted that, with changes of the road level, the improvement in road handling is relatively smaller than that of ride comfort. This may be interpreted as follows: although the groundhook control strategy involves setting an imaginary inertial reference and installing the corresponding damping between the unsprung mass and the inertial reference, as shown in Figure 1(a), the simulation results reveal that the velocity of the road profile is much larger than the velocity of the unsprung mass, which means that the unsprung mass is affected by both road input and the suspension system. In this case, the influence of the road profile velocity cannot be ignored. It should similarly be noted that for the skyhook control, the sprung mass is only affected by the suspension system. In this case, in order to better eliminate the influence of the road input, one possible solution is to alter the groundhook force expression from $F_{\text {grd }}=c_{\text {grd }} \dot{x}_{w}$ to $F_{\text {grd }}=c_{\text {grd }}\left(\dot{x}_{w}-\dot{x}_{r}\right)$. The simulation results however show that, although this method can considerably improve road handling, the changes in damping force will 
also influence the sprung mass, significantly increasing the acceleration of the sprung mass. In this case, the proposed method may prove more suitable.

\section{Conclusion}

In this paper, an adaptive semiactive suspension system control strategy based on road profile estimation is proposed. Analytical expressions for ride comfort, road handling, and rattle space with respect to road conditions are derived, in order to depict the system's response to random road excitation. The choice of control gains $\left[c_{\text {sky }}, c_{\text {grd }}\right]$ for different road levels is then transformed into a MOOP, and NSGAII is applied to solve this problem. A new road profile estimation method is moreover proposed to accompany the hybrid control strategy, which estimates the road profile in the time domain utilising an inverse ANFIS model and further applies wavelet transforms to calculate the input road level. A specially designed road profile with five different levels is utilised to verify the proposed control and road estimation methods, and a Kalman filter is applied to observe the unknown system states. The simulation results reveal that the proposed road estimation method can accurately and rapidly identify the road level, and based on the estimated road level, the hybrid control strategy can adaptively alter the control gains to suit different road levels. Due to the interactions of the damping force for the sprung mass and the unsprung mass, ride comfort and road handling cannot both be improved simultaneously.

The main contributions of this paper are as follows: firstly, to solve the problem of choice of damping coefficients for hybrid control, the analytical expressions for ride comfort, road handling, and rattle space are presented and corresponding damping coefficients are calculated by NSGA-II. Secondly, a new road level classification method is developed, which can be widely used for randomly profiled roads. Finally, suggestions are made regarding how to effectively select control gains for the semiactive suspension system and their interaction with road estimation.

Further research may proceed in the following aspects:

(1) As the control strategy presented here is derived based on a quarter vehicle model, when applied to a full vehicle model, the influence of the proposed control strategy on pitch and roll angle for this control strategy requires further study.

(2) As can be seen from Section 3, the suspension system is modelled linearly. It is generally accepted however that actual vehicle suspension systems are typically nonlinear, displaying variance over time. To account for this, the Kalman filter could be modified to an EKF (Extended Kalman Filter) in future work. It should be noted that the proposed method of road profile estimation can however be used for nonlinear systems only if the training signal is comprehensive.

(3) Since the proposed method is based only on theoretical analysis and validation via simulation, an actual bench test for the quarter vehicle model is needed in the future to validate the proposed control strategy.
(4) The control frequency is $1000 \mathrm{~Hz}$ in this paper, and since the delay of realistic controllable damper might be larger than this control interval, that is, $1 \mathrm{~ms}$, to realize hybrid control in real suspension system, we will conduct some experiments to investigate the influence of control frequency and control delay in the near future.

\section{Conflict of Interests}

The authors declare that there is no conflict of interests regarding the publication of this paper.

\section{References}

[1] S. M. Savaresi, C. P. Vassal, C. Spelta et al., Semi-Active Suspension Control Design for Vehicles, Elsevier, Oxford, UK, 2010.

[2] E. Guglielmino, T. Sireteanu, C. W. Stammers, G. Ghita, and M. Giuclea, Semi-Active Suspension Control: Improved Vehicle Ride and Road Friendliness, Springer, London, UK, 2008.

[3] E. M. Elbeheiry and D. C. Karnopp, "Optimal control of vehicle random vibration with constrained suspension deflection," Journal of Sound and Vibration, vol. 189, no. 5, pp. 547-564, 1996.

[4] M. Gobbi and G. Mastinu, "Analytical description and optimization of the dynamic behaviour of passively suspended road vehicles," Journal of Sound and Vibration, vol. 245, no. 3, pp. 457481, 2001.

[5] A. Turnip and K. S. Hong, "Road-frequency based optimisation of damping coefficients for semi-active suspension systems," International Journal of Vehicle Design, vol. 63, no. 1, pp. 84-101, 2013.

[6] International Organization for Standardization, Mechanical Vibration and Shock-Evaluation of Human Exposure to WholeBody Vibration, International Organization for Standardization, London, UK, 1997.

[7] D. Karnopp, M. J. Crosby, and R. A. Harwood, "Vibration control using semi-active force generators," Journal of Engineering for Industry, vol. 96, no. 2, pp. 619-626, 1974.

[8] P. W. Nugroho, W. Li, H. Du, G. Alici, and J. Yang, "An adaptive neuro fuzzy hybrid control strategy for a semiactive suspension with magneto rheological damper," Advances in Mechanical Engineering, vol. 6, Article ID 487312, 2014.

[9] D. Hrovat, "Survey of advanced suspension developments and related optimal control applications," Automatica, vol. 33, no. 10, pp. 1781-1817, 1997.

[10] L. H. Nguyen, K.-S. Hong, and S. Park, "Road-frequency adaptive control for semi-active suspension systems," International Journal of Control, Automation and Systems, vol. 8, no. 5, pp. 1029-1038, 2010.

[11] J. D. Robson and C. J. Dodds, "The description of road surface roughness," Journal of Sound and Vibration, vol. 31, no. 2, pp. 175-183, 1973.

[12] R. S. Sharp and D. A. Crolla, "Road vehicle suspension system design-a review," Vehicle System Dynamics, vol. 16, no. 3, pp. 167-192, 1987.

[13] K.-S. Hong, H.-C. Sohn, and J. K. Hedrick, "Modified skyhook control of semi-active suspensions: a new model, gain scheduling, and hardware-in-the-loop tuning," Journal of Dynamic Systems, Measurement and Control, vol. 124, no. 1, pp. 158-167, 2002. 
[14] A. A. Aly and F. A. Salem, "Vehicle suspension systems control: a review," International Journal of Control, Automation, and Systems, vol. 2, no. 2, pp. 46-54, 2013.

[15] L. Balamurugan and J. Jancirani, "An investigation on semiactive suspension damper and control strategies for vehicle ride comfort and road holding," Proceedings of the Institution of Mechanical Engineers. Part I: Journal of Systems and Control Engineering, vol. 226, no. 8, pp. 1119-1129, 2012.

[16] M. Valášek, M. Novák, Z. Šika, and O. Vaculín, "Extended ground-hook-new concept of semi-active control of truck's suspension," Vehicle System Dynamics, vol. 27, no. 5-6, pp. 289303, 1997.

[17] Y. Hurmuzlu and O. D. Nwokah, The Mechanical Systems Design Handbook: Modeling, Measurement, and Control, CRC Press, Danvers, Mass, USA, 2001.

[18] H. Du, K. Yim Sze, and J. Lam, "Semi-active $H_{\infty}$ control of vehicle suspension with magneto-rheological dampers," Journal of Sound and Vibration, vol. 283, no. 3-5, pp. 981-996, 2005.

[19] N. Giorgetti, A. Bemporad, H. E. Tseng, and D. Hrovat, "Hybrid model predictive control application towards optimal semiactive suspension," International Journal of Control, vol. 79, no. 5, pp. 521-533, 2006.

[20] M. Canale, M. Milanese, and C. Novara, "Semi-active suspension control using 'fast' model-predictive techniques," IEEE Transactions on Control Systems Technology, vol. 14, no. 6, pp. 1034-1046, 2006.

[21] M. Ahmadian and N. Vahdati, "Transient dynamics of semiactive suspensions with hybrid control," Journal of Intelligent Material Systems and Structures, vol. 17, no. 2, pp. 145-153, 2006.

[22] V. Sankaranarayanan, E. M. Emekli, L. Güvenç et al., "Semiactive suspension control of a light commercial vehicle," IEEE/ASME Transactions on Mechatronics, vol. 13, no. 5, pp. 598-604, 2008.

[23] K. Deb, A. Pratap, S. Agarwal, and T. Meyarivan, "A fast and elitist multiobjective genetic algorithm: NSGA-II," IEEE Transactions on Evolutionary Computation, vol. 6, no. 2, pp. 182197, 2002.

[24] K. Deb, Multi-Objective Optimization Using Evolutionary Algorithms, John Wiley \& Sons, Chichester, UK, 2001.

[25] Y. Qin, R. Langari, and L. Gu, "The use of vehicle dynamic response to estimate road profile input in time domain," in Proceedings of the ASME Dynamic Systems and Control Conference (DSCC '14), p. 8, San Antonio, Tex, USA, October 2014.

[26] International Organization for Standardization, Mechanical Vibration-Road Surface Profiles-Reporting of Measured Data, International Organization for Standardization, London, UK, 1995.

[27] M. Mitschke and H. Wallentowitz, Dynamik der Kraftfahrzeuge, Springer, Berlin, Germany, 1972.

[28] P. Michelberger, L. Palkovics, and J. Bokor, "Robust design of active suspension system," International Journal of Vehicle Design, vol. 14, no. 2-3, pp. 145-165, 1993.

[29] Z. C. Wu, S. Z. Chen, L. Yang, and B. Zhang, "Model of road roughness in time domain based on rational function," Transaction of Beijing Institute of Technology, vol. 29, no. 9, pp. 795-798, 2009.

[30] M. Ahmadian and C. A. Pare, "A quarter-car experimental analysis of alternative semiactive control methods," Journal of Intelligent Material Systems and Structures, vol. 11, no. 8, pp. 604-612, 2001.
[31] J.-H. Koo, M. Ahmadian, M. Setareh, and T. M. Murray, "In search of suitable control methods for semi-active tuned vibration absorbers," Journal of Vibration and Control, vol. 10, no. 2, pp. 163-174, 2004.

[32] T. Butsuen, The design of semi-active suspensions for automotive vehicles [Ph.D. thesis], Massachusetts Institute of Technology, Cambridge, Mass, USA, 1989.

[33] R. Rajamani, Vehicle Dynamics and Control, Springer, New York, NY, USA, 2011.

[34] C. D. Mcgillem and G. R. Cooper, Probabilistic Methods of Signal and System Analysis, Oxford University Press, Oxford, UK, 1986.

[35] R. G. Brown and P. Y. Hwang, Introduction to Random Signals and Applied Kalman Filtering: With MATLAB Exercises and Solutions, John Wiley \& Sons, New York, NY, USA, 1997.

[36] K. Deb, Optimization for Engineering Design: Algorithms and Examples, PHI Learning Pvt. Ltd., New Delhi, India, 2012.

[37] C. C. Coello, G. B. Lamont, and V. D. A. Van, Evolutionary Algorithms for Solving Multi-Objective Problems, Springer, New York, NY, USA, 2007.

[38] M. Doumiati, A. Victorino, A. Charara, and D. Lechner, "Estimation of road profile for vehicle dynamics motion: experimental validation," in Proceedings of the American Control Conference (ACC '11), pp. 5237-5242, San Francisco, Calif, USA, July 2011.

[39] H. Imine, Y. Delanne, and N. K. M'Sirdi, "Road profile input estimation in vehicle dynamics simulation," Vehicle System Dynamics, vol. 44, no. 4, pp. 285-303, 2006.

[40] A. González, E. J. O’Brien, Y.-Y. Li, and K. Cashell, "The use of vehicle acceleration measurements to estimate road roughness," Vehicle System Dynamics, vol. 46, no. 6, pp. 483-499, 2008.

[41] A. Rabhi, N. K. M'sirdi, L. Fridman, and Y. Delanne, "Second order sliding mode observer for estimation of road profile," in Proceedings of the International Workshop on Variable Structure Systems (VSS '06), pp. 161-165, Alghero, Italy, June 2006.

[42] G. Koch, T. Kloiber, and B. Lohmann, "Nonlinear and filter based estimation for vehicle suspension control," in Proceedings of the 49th IEEE Conference on Decision and Control (CDC '10), pp. 5592-5597, IEEE, Atlanta, Ga, USA, December 2010.

[43] R. McCann and S. Nguyen, "System identification for a modelbased observer of a road roughness profiler," in Proceedings of the IEEE Region 5 Technical Conference (TPS '07), pp. 336-343, April 2007.

[44] J.-S. R. Jang, "ANFIS: adaptive-network-based fuzzy inference system," IEEE Transactions on Systems, Man and Cybernetics, vol. 23, no. 3, pp. 665-685, 1993. 

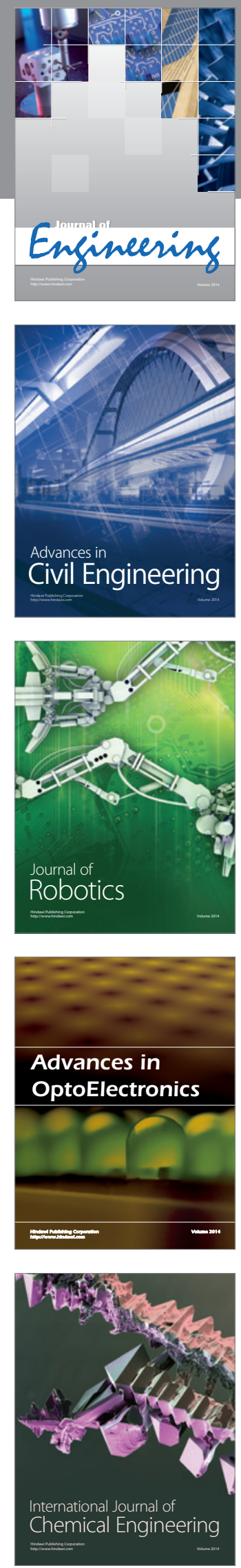

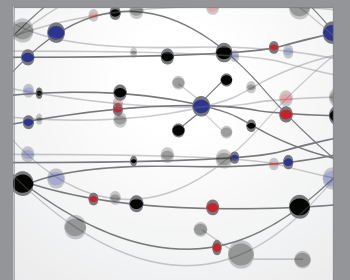

The Scientific World Journal
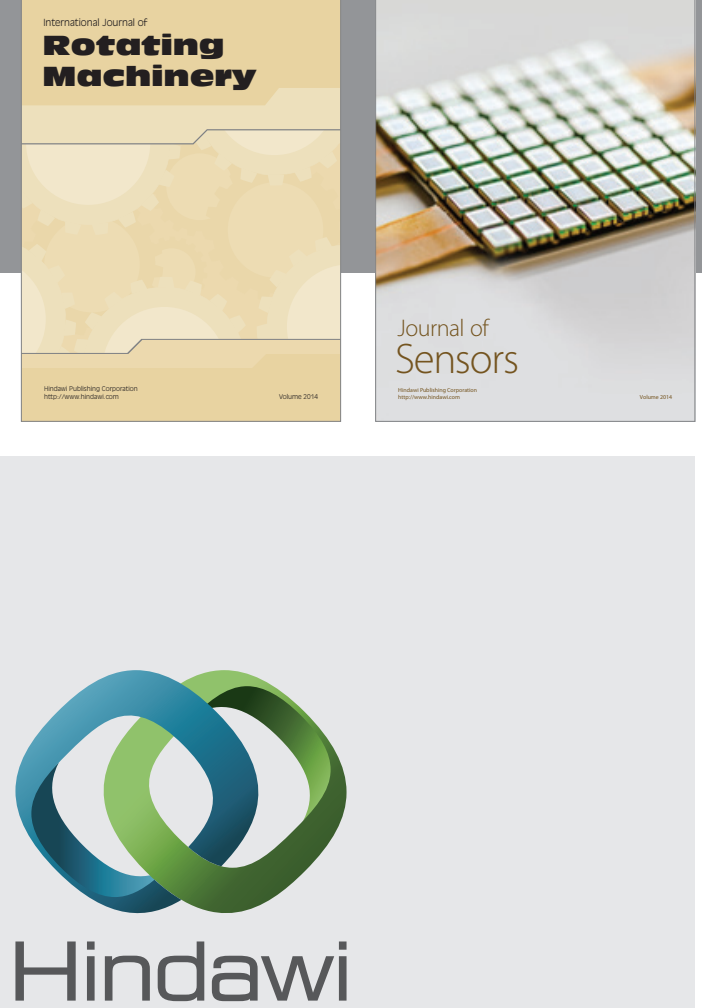

Submit your manuscripts at http://www.hindawi.com
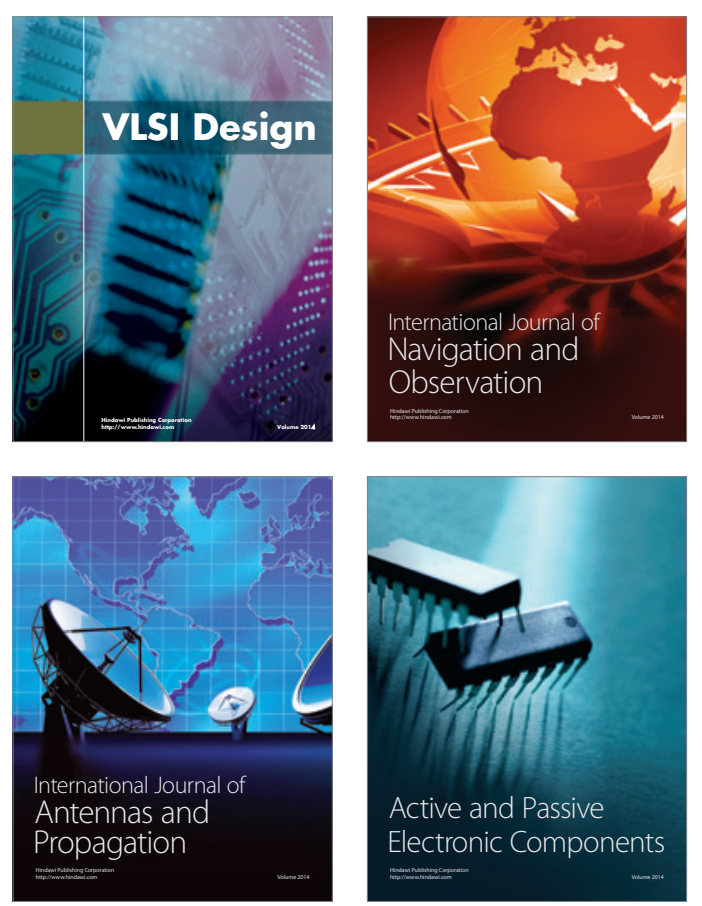
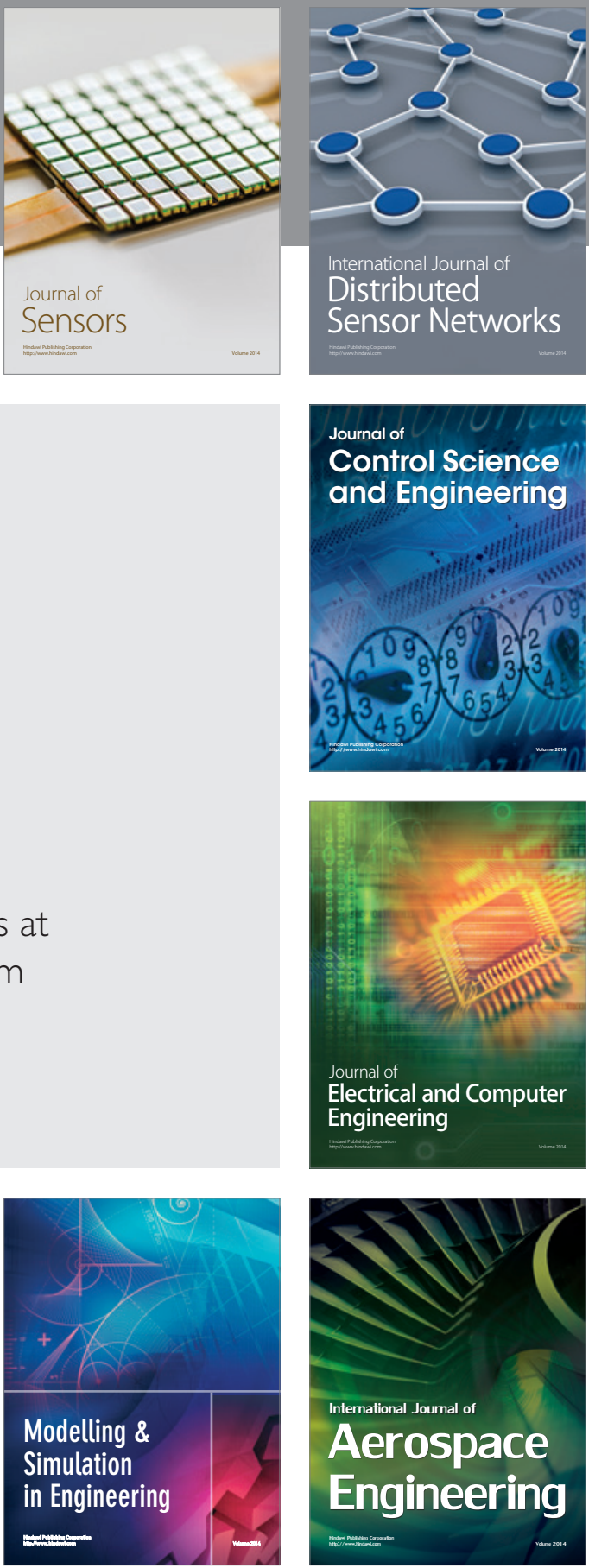

Journal of

Control Science

and Engineering
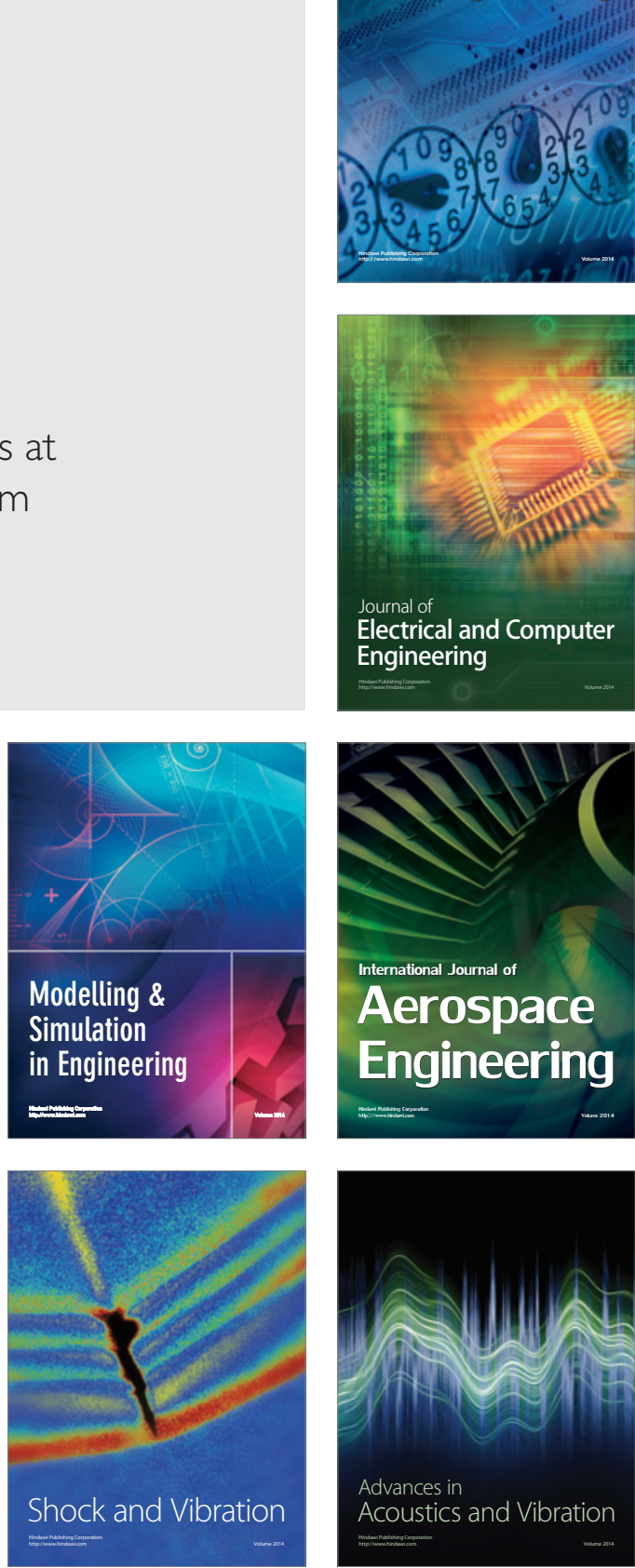